\section{Biliary tumor thrombus of hepatocellular carcinoma containing lipiodol mimicking a calcified bile duct} stone

A 57-year-old man with liver cirrhosis caused by chronic hepatitis $\mathrm{B}$ infection was admitted to Hepato-Biliary-Pancreatic Surgery Division of the University of Tokyo Hospital to undergo preoperative transarterial chemoembolization (TACE) against recurrent hepatocellular carcinoma (HCC) with biliary invasion. A single HCC measuring $3 \mathrm{~cm}$ was located in segment VIII of the liver ( $\nabla$ Fig. 1). Selective TACE using farmorubicin and lipiodol was performed from the arterial branch of segment VIII. Five days after TACE had been performed, the patient suffered sudden epigastric pain with obstructive jaundice. Computed tomography (CT) revealed a high-density mass in the distal common bile duct ( $\bullet$ Fig. 2 ).

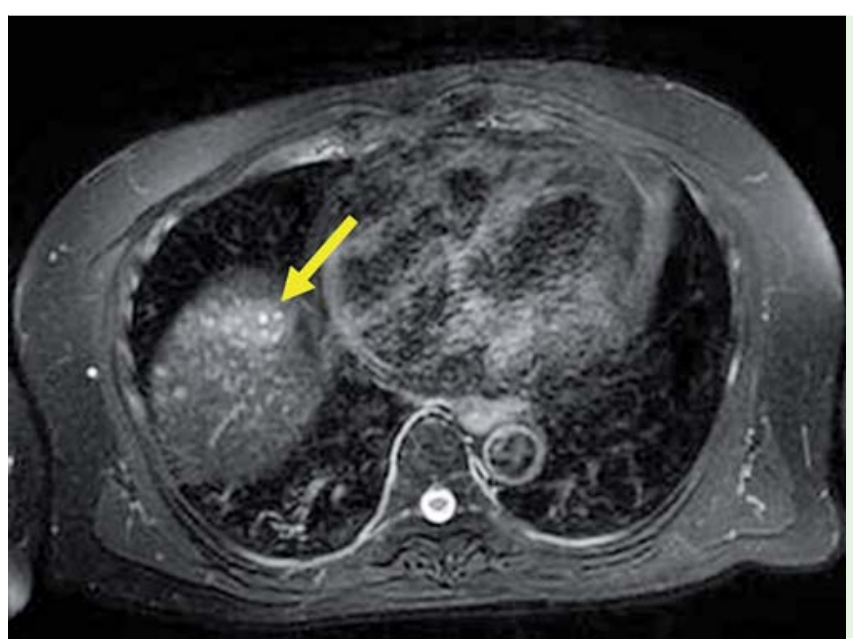

Fig. 1 T2-weighted magnetic resonance imaging showed a $3 \mathrm{~cm}$ high-intensity hepatocellular carcinoma in segment VIII of the liver.

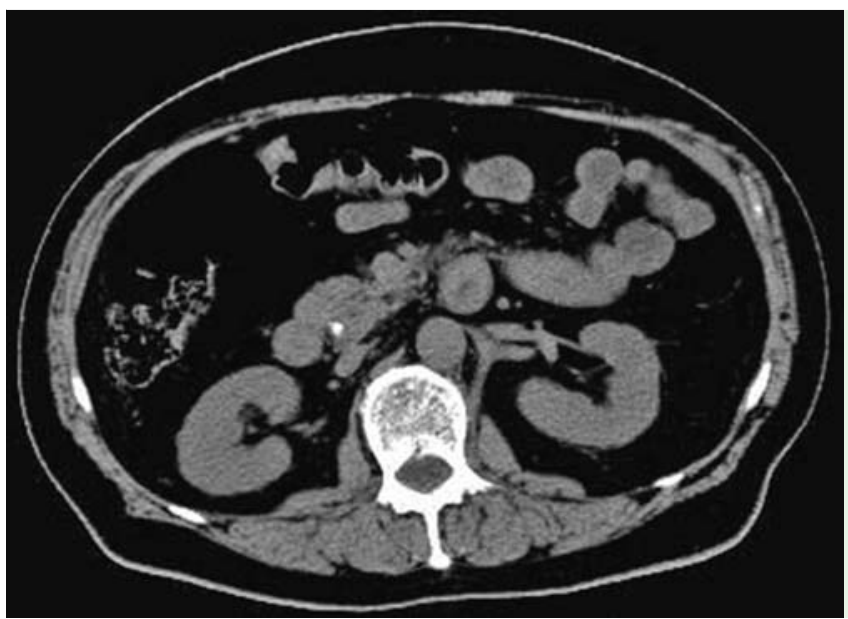

with liver cirrhosis, we performed EPBD with a $6 \mathrm{~mm}$ balloon [1,2]. After EPBD, yellowish tissue was obtained using a retrieval balloon catheter ( Fig.5). This tissue was collected and histopathological examination revealed it to be HCC.

It is rare for a fragment of biliary tumor thrombus to drop into the distal common bile duct in a patient with HCC [3]. Our patient showed a rare instance of biliary tumor thrombus of HCC containing lipiodol mimicking a calcified biliary stone at the distal common bile duct.

Endoscopy_UCTN_Code_CCL_1AZ_2AI

Competing interests: None

T. Sasaki ${ }^{1}$, N. Takahara ${ }^{1}$, Y. Kawaguchi ${ }^{2}$, H. Takao ${ }^{3}$, K. Matsusaka ${ }^{4}$, K. Miyabayashi $^{1}$, N. Yamamoto', K. Hirano ${ }^{1}$, H. Isayama ${ }^{1}$, J. Kaneko², N. Kokudo², K. Kazuhiko ${ }^{1}$

${ }^{1}$ Department of Gastroenterology, Graduate School of Medicine,

The University of Tokyo

${ }^{2}$ Hepato-Biliary-Pancreatic Surgery Division, Department of Surgery, Graduate School of Medicine, The University of Tokyo ${ }^{3}$ Department of Radiology, Graduate School of Medicine, The University of Tokyo

${ }^{4}$ Department of Pathology and Diagnostic Pathology, Graduate School of Medicine, The University of Tokyo

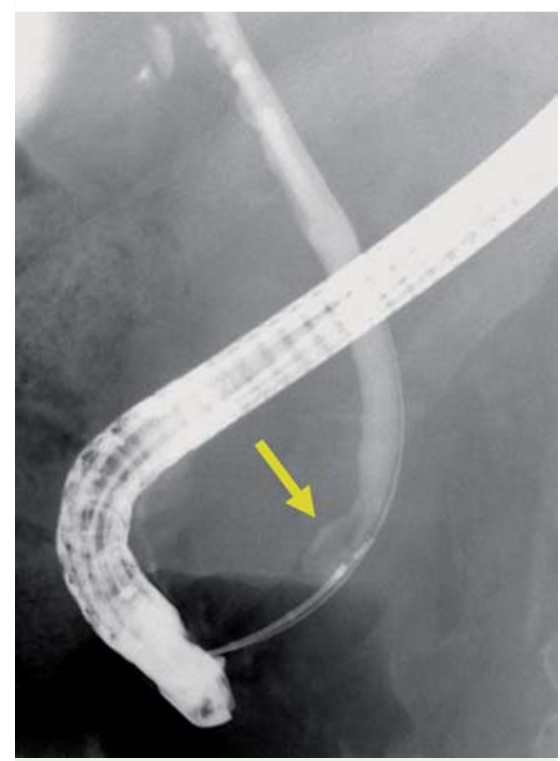

Fig. 3 Endoscopic retrograde cholangiopancreatography detected an arrow-shaped defect in the distal common bile duct. 


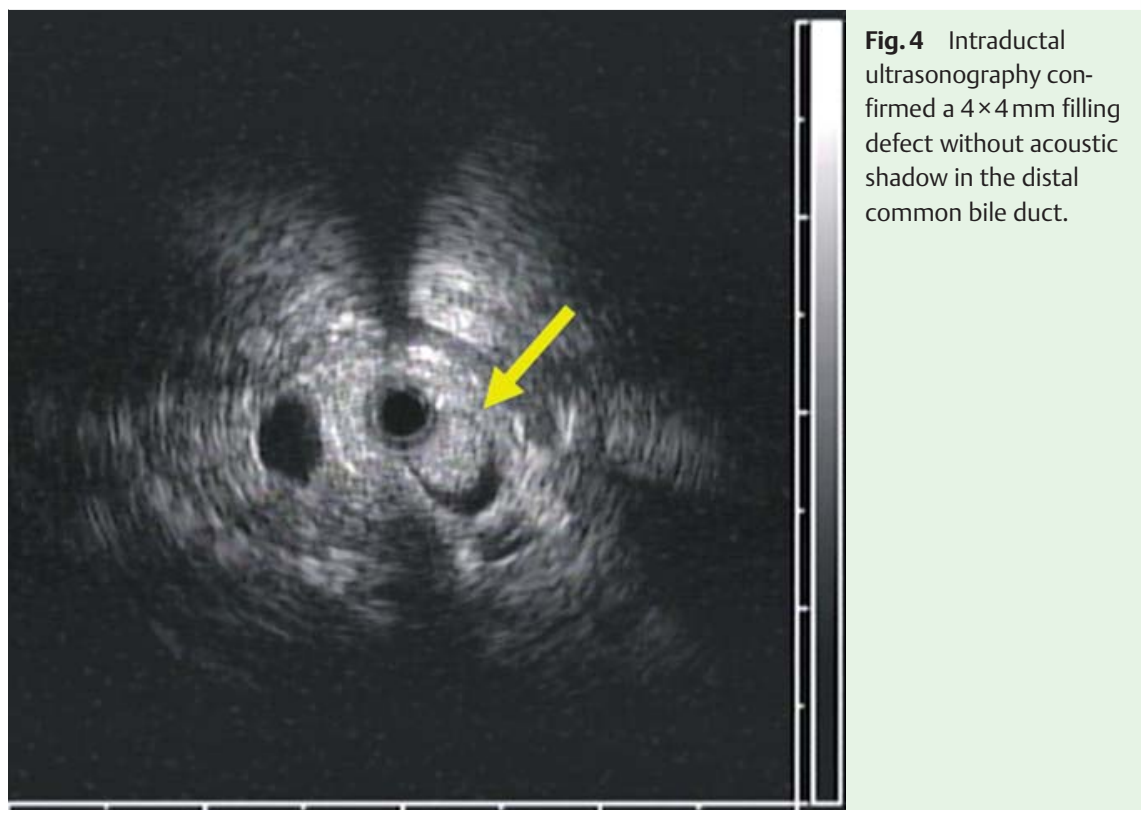

\section{References}

1 Tsujino T, Kawabe T, Komatsu $Y$ et al. Endoscopic papillary balloon dilation for bile duct stone: immediate and long-term outcomes in 1000 patients. Clin Gastroenterol Hepatol 2007; 5: 130-137

2 Sasahira N, Tada M, Yoshida $H$ et al. Extrahepatic biliary obstruction after percutaneous tumour ablation for hepatocellular carcinoma: aetiology and successful treatment with endoscopic papillary balloon dilatation. Gut 2005; 54: 698-702

3 Kogure H, Miyabayashi K, Tsujino $T$ et al. Spontaneous dislodgement of a biliary tumor in a patient with hepatocellular carcinoma. Endoscopy 2011; 43 (Suppl. 02): $232-233$

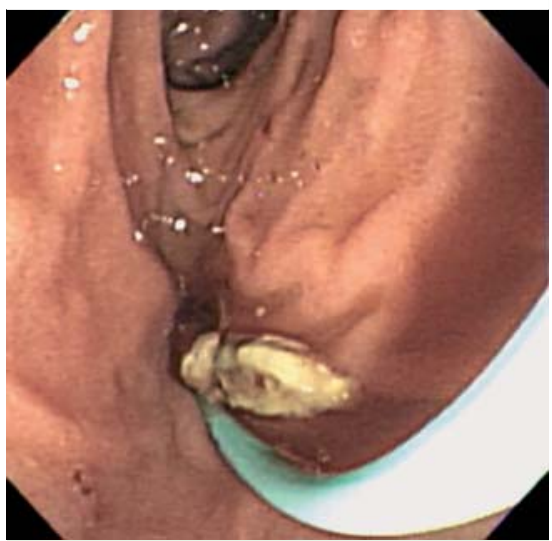

Fig. 5 Yellowish tissue was obtained using a retrieval balloon catheter.

\section{Bibliography}

DOI http://dx.doi.org/

10.1055/s-0032-1309761

Endoscopy 2012; 44: E250-E251

(c) Georg Thieme Verlag KG

Stuttgart · New York

ISSN 0013-726X

\section{Corresponding author}

\section{T. Sasaki, MD, PhD}

Department of Gastroenterology

Graduate School of Medicine

The University of Tokyo

7-3-1 Hongo, Bunkyo-ku

Tokyo 113-8655

Japan

Fax: +81-3-38140021

sasakit-tky@umin.ac.jp 